\title{
AN OVERVIEW ON POWER QUALITY ISSUES IN POWER GRIDS CONNECTED WITH NON-CONVENTIONAL ENERGY SOURCES
}

\author{
Madha Chesti \\ Research scholar \\ Department of electrical engineering \\ SSM college of engineering, \\ Parihaspora, Pattan, J\& K INDIA
}

\author{
Ishtiyaq Shafi Rafiqi \\ Associate professor \\ Department of electrical engineering \\ SSM college of engineering, \\ Parihaspora, Pattan, J\& K INDIA
}

\begin{abstract}
The term power quality is inescapable when it comes to Electric power system. The main intent of the researchers and different organizations all over the world is to provide the consumers with quality power. Practically, it is difficult to achieve quality power as there are number of issues associated with Electric power system called as power quality problems. Harmonics, transients, use of non linear loads, interruptions etc. are the factors which cause disturbances in the electric power system and thus leads to the deterioration in the quality of power. These disturbances are the major challenges to the power quality and must be analyzed properly before mitigating them. The paper has put emphasis on the major disturbances in the power grids. The paper is also considerate about the causes and effect of these disturbances in the power grids.
\end{abstract}

\section{KEYWORDS-POWER QUALITY, NON LINEAR LOADS, HARMONICS, TRANSIENTS, INTERRUPTIONS, VOLATGE SAG, VOLTAGE SWELL, VOLTAGE SPIKE}

\section{ITNRODUCTION}

Electric power systems are commonly referred or known by another term called as Power grids. It simply means the generation of electric power at $0.6 \mathrm{kvto} 11 \mathrm{kv}$, transmission of the generated electrical power at $132 / 400 \mathrm{kv}$ and distribution of the same power at $66 / 11 \mathrm{kv}$.But this actually defines an isolated Electric power system. In reality, Electric power system forms a network i.e. they are interlinked. It indeed is a humongous system and has got its own essence. The term which is worth the discussion is undeniably PQ (Power quality) as it holds the basis of electric power system. The term power quality stands for the electric power that drives an electrical device and the device's ability to function properly with that electric power. However, it doesn't stop here as many organizations and researchers have defined power quality in different ways. Power quality refers to the quality of electrical energy in power system. The waveform of the most perfect electrical energy as the ideal symmetric sinusoidal waveform. IEEE -Std 1100 provides the PQ definition considering the powering and grounding of sensitive equipments so that operation takes place smoothly.IEC 6100 defines power quality as the electromagnetic compatibility of equipment so that it can work satisfactorily in electromagnetic surroundings. Moreover, in practice the term power quality has got its own characteristics, it can be either good or bad. The latter giving rise to power quality problems in power grids. Before going for the nuanced analysis of power quality problems in power grids, it would be appropriate to know what good electric power quality stands for. It simply means as a steady supply voltage that stays within the prescribed range, steady AC frequency and smooth voltage curve waveform (sine wave). Thus, a good power does not show any deviation from the standard conditions.

Since 1968, we are familiar with the term power quality issues. According to an elementary definition, it can be defined as - any patent problem that arises due to power quality. Any deviation from the standard conditions of power quality can interject problems in any electrical power system. Uninterrupted sinusoidal voltage of constant amplitude is the chief requirement of the consumers. Power utility companies are working endlessly to meet the demand. However, the extensive use of power semiconductor devices are not allowing to realize the demands of consumers as these 
devices tend to distort the waveform. Unnecessary tripping due to supply voltage disturbance is also termed as bad power quality by the consumers. Terms such as current or voltage quality are also used instead of power quality. But to be precise, it is both the current and voltage quality that constitutes power quality. The deviation of either current or voltage quality from its ideal can ensue problems in Electric power system. The aim of this paper is to enlighten the readers about the disturbances in power grids.

\section{WHY TO STUDY POWER QUALITY?}

One must hold a good full- fledged knowledge of power quality because our day to day work is dependent on electrical power. There are endless equipments that run on electrical power. In order to study the behaviour of various equipments the knowledge of power quality is must. Electrical loads must show coherence and synchronization with electrical system. Any dip in the quality of power can give rise to unavoidable situations in places like hospitals, schools business sectors etc. Power quality problems must be rectified immediately as any delay in the process can cause a major mishap. Conditions such as wiring, grounding or bonding problems must be ameliorated once they are detected

\section{POWER QUALITY ISTURBANCES}

\section{1) TRANSIENTS}

An abrupt change in the system due to power blackouts, addition or removal of heavy loads or due to any defect in the system leads to the aberration of sinusoidal wave form from its actual form. This is called transient. Transients can arise any system either internally or externally . Lightning is known to induce transients in electric power system . During lightning, voltage in power lines may shoot up to several hundred KV for a duration of 100 micro seconds or more. Internal sources can also cause transients in a system. Loads which are inductive in nature can ensue transients. Inductive devices such as motors and transformers whenever turned on or off, produce transient. An energizing transformer can bring forth transient in generous amount. Fault in breakers, or weak connections in the distribution systems can give rise to transients. The problem of transient can be alleviated by devices such as Surge arrestor, Transient voltage, Surge suppressor, Voltage stabilizer, Voltage regulator etc. Fig 1 shows transients

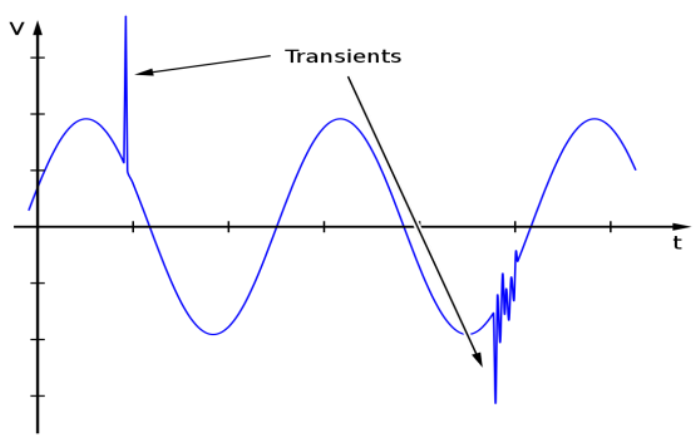

Fig 1:Transients

\section{2) VOLTAGE SAG OR DIP}

Fall in the voltage from its nominal RMS voltage is termed as voltage sag. A dip in the voltage level from $10 \%$ or more marks the problem of voltage sag in an electrical power system . Voltage sag usually lasts for one half cycle to one minute. Thus, voltage sag is a momentary drop in the voltage. Whenever a fault runs into any transmission or distribution system, voltage sag becomes unavoidable. Parallel feeders in distribution network tend to produce voltage sag. Motors, heavy loads, non linear loads may spring up the problem of voltage dips. Fly wheels, Voltage resistor, STATCOM, UPS etc are put in practice to overcome the problem of voltage dips. Fig 2 shows voltage sag

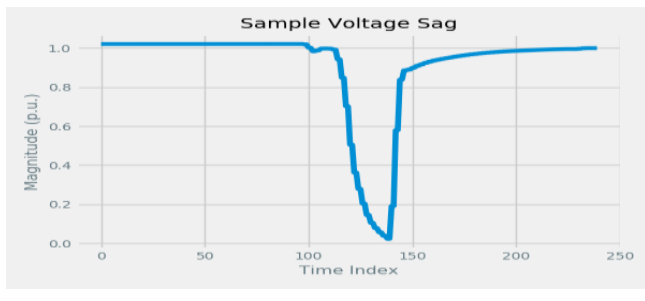

Fig 2:Voltage Sag

\section{3) HARMONICS}

It is a type of waveform distortion. Harmonics are sinusoidal voltages or currents having frequencies that are integer multiples of the fundamental frequency. Non linear loads tens to induce harmonics in the system. When voltage or current have frequency components which are not integer multiples of the fundamental frequency such harmonics are called interharmonics. Harmonics not only cause distortion in the system but they tend to heat up the system which further gives rise to excessive power loss in the 


\section{International Journal of Engineering Applied Sciences and Technology, 2021 \\ Vol. 6, Issue 4, ISSN No. 2455-2143, Pages 328-333 \\ Published Online August 2021 in IJEAST (http://www.ijeast.com)}

system. Harmonics also may also causes damage to the electrical equipments. Devices such as speed drivers in fans, television, synchronous machines, fluorescent lamps etc are called non linear loads as they draw power which is not in the form of sine wave. The major sources of interharmonics are Induction furnaces, cycloconverters, static frequency converters etc. To overcome the problem of harmonics, devices such as Induction filter, resonance filter, series line reactors etc. are employed. Fig 3 and Fig 4 show harmonics and interharmonics respectively.

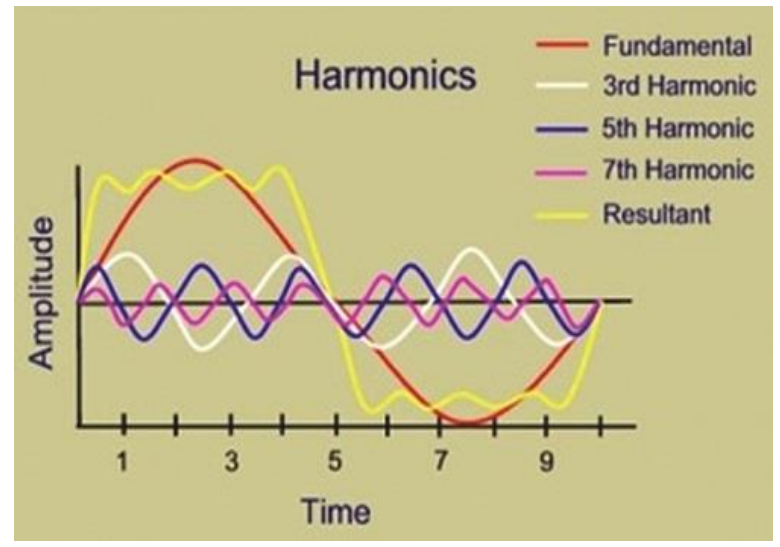

Fig 3:Harmonics

\section{Deviation (\%)}

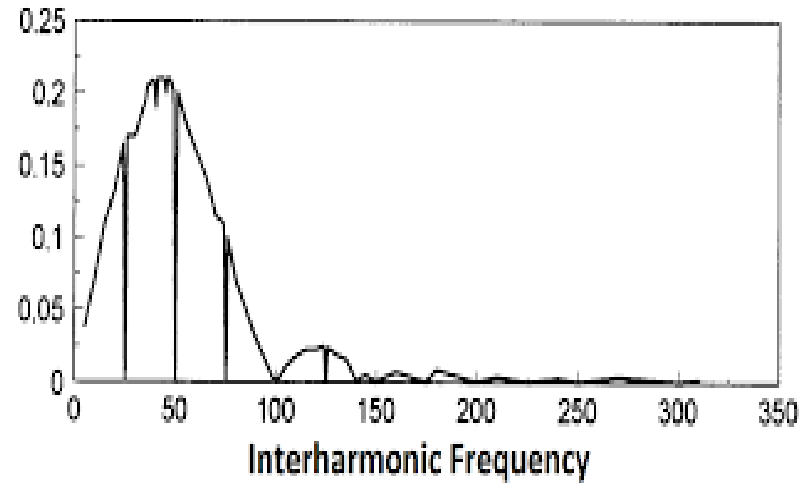

Fig 4:Interharmonic Frequency

\section{4) VOLTAGE FLUCTUATIONS}

A change in the envelope or value of voltage is termed as voltage fluctuation. The term flicker is also associated with the voltage fluctuation as it is an unwanted result of the voltage fluctuation. Dimming of lights or fluctuation in the intensity of light is referred to as flicker. Flicker is conspicuous to the human eye .Loads such as welders, induction motor ,boilers, etc tend to rapidly vary the magnitude of load current and cause voltage variation in the system. Dynamic voltage regulator, STATCOM etc are used to mitigate the problem of voltage fluctuations

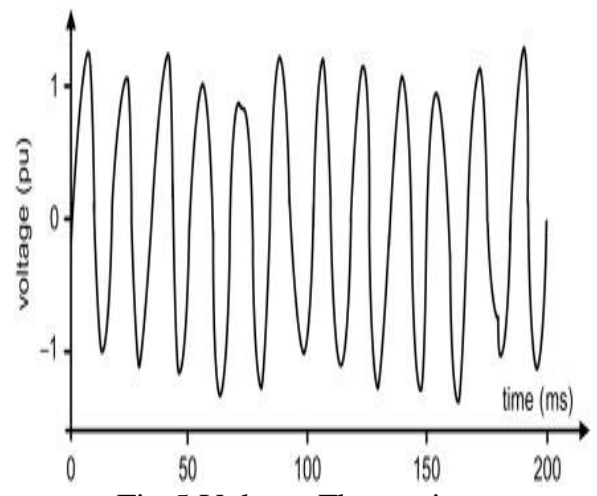

Fig 5:Voltage Fluctuations

\section{5) VOLTAGE SPIKE}

It is a sudden, rapid change in the value of voltage . The duration of voltage spike is not that long. This abrupt change in the value of voltage may last for few milliseconds. The term surge is often used instead of voltage spike. Energy induced by magnetic field in any circuit is held responsible for voltage spikes. Moreover, switching, short circuit or power factor correction capacitor may give rise to voltage spike .Surge protectors are the devices which are used to protect the system from voltage spikes. Fig 6 corresponds to voltage spike/ surge .

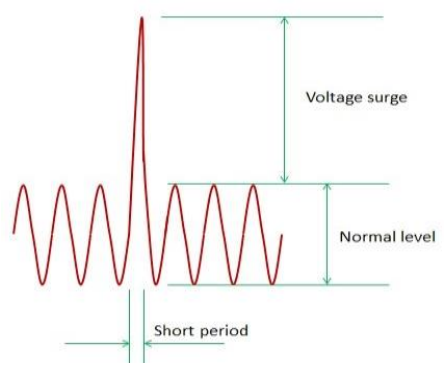

Fig 6:Voltage Surge

6) VOLTAGE SWELL

Equipments employed in the field of electric power system work on some specific voltage known as nominal voltage. Whenever, there is a transistory increase in the RMS voltage by a value of $10 \%$ or more 


\section{International Journal of Engineering Applied Sciences and Technology, 2021 \\ Vol. 6, Issue 4, ISSN No. 2455-2143, Pages 328-333 \\ Published Online August 2021 in IJEAST (http://www.ijeast.com)}

than the rated voltage for a duration of half cycle to one minute, begets the problem of voltage swell in the power grids. Voltage swell and Voltage sag are diametrically opposite. The factors responsible for voltage swell are switching of heavy loads ,energizationof large capacitor banks and rapid interruption in the value of current tends to produce large voltage .Mitigating measures include Voltage transformer, UPS, Fly wheels etc.Fig 7 corresponds to voltage swell.

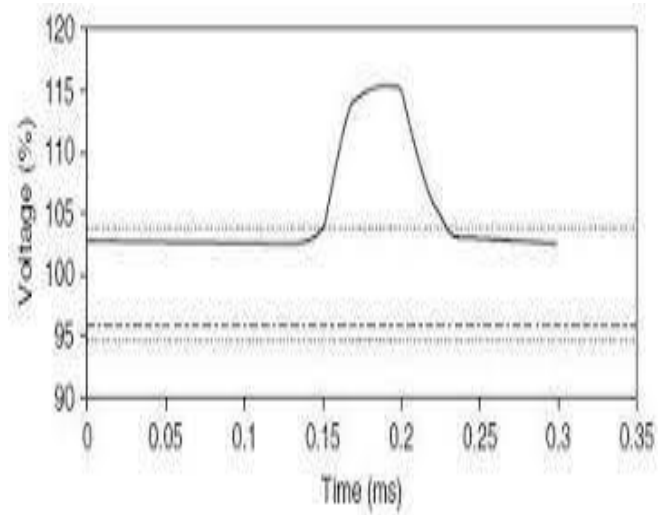

Fig 7:Voltage Swell

\section{7) MICRO INTERRUPTIONS}

Interruption of electrical supply for time period of few milliseconds to one or two seconds. These interruptions are tempoary and ususally persist for short durations. Theerefore, these interruptions are also called short duration interruptions. Short duration interruptions may affect the working of equipmentslike computers, PLC, ASD etc . It may also lead to the loss of data in such sensitive equipments. Flashovers, lightning and insulation failures are mainly responsible for micro interruptions.Fig8 shows micro interruptions .

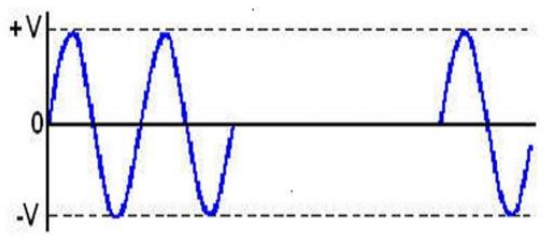

Fig 8: Voltage Interruptions

\section{8) LONG INTERRUPTIONS}

Dropping down of the supply voltage from some specific value to zero for more than a minute is termed as long interruption . These interruptions are permanent and hence are also called as sustained interruptions .Natural calamities such as storms renders the electric power system with faults which further induces the customer equipment failure in power system and gives rise to long interruptions.Fig 9 corresponds long interruptions .

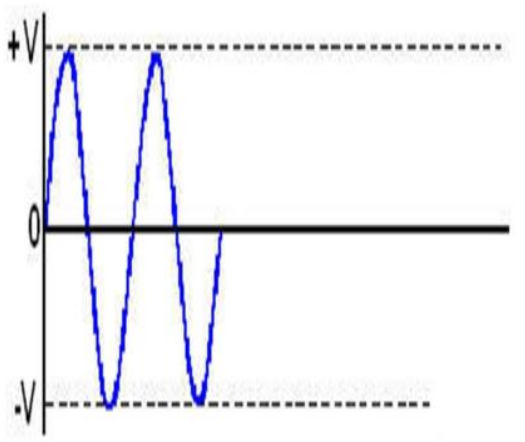

Fig 9:Long voltage interruptions

\section{9) NOISE}

Noise is an undesirable electrical signal which when gets coupled into any of the circuits in the electric power system tends to distort the voltage waveform . The boradband spectral content of undesirable signlas is lower than $200 \mathrm{kHz}$. The major sources of electrical noise are loads with rectifiers, switching, arching equipments etc. The problem of noise can be overcome by the use of line conditioners and Isolated transformers .

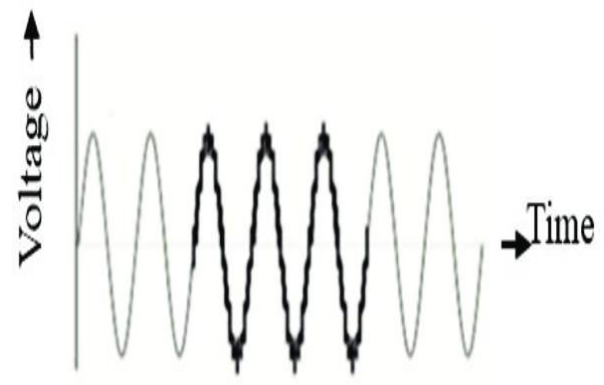

Fig 10:Noise Signal in Voltage waveform 


\section{International Journal of Engineering Applied Sciences and Technology, 2021 Vol. 6, Issue 4, ISSN No. 2455-2143, Pages 328-333 \\ Published Online August 2021 in IJEAST (http://www.ijeast.com)}

\section{STEPS TO RECTIFY POWER QUALITY PROBLEMS}

1) Continuous and extensive monitoring ( Local monitoring and System monitoring ) of different power system quantities .

2) Detection and indentification of power quality related disturbances and categorizing them.

3) Analysis of identified problems to their probable causes.

4) Prevention and correction of thr probable cause either automatically or manually.

\section{CONCLUSION}

The paper has described PQ in the best possible way .Different power quality problems in power grids is an integral part of this paper. The paper has put light on various devices and steps to alleviate the problems in power grids .

\section{ACKNOWLEDGEMENT}

The author is immensely thankful to $\mathrm{Mr}$ Ishtiyaq Shafi Rafiqi for showing an intense support now and then. He not only played a role of mentor in writing this paper but indeed proved a motivator throughout.

\section{REFERENCES}

1)E. Prathibha( Dept. of EEE, VTU university) and A. Manjunath ( Dept. of EEE , VTU University) ( November 2014)., AN OVERVIEW OF POWER QUALITY ISSUES IN SMART GRID , International Journal of Innovative research in Advanced Engineering ( IJIRAE ) ISSN : 2349-2163 Volume 1 Issue 10

2)Ravikanth Mallajoshula, I. E. S . Niadu, (December 2019).,POWER QUALITY ISSUES IN POWER SYSTEMS ,International Journal of Innovative Technology and Exploring Engineering (IJTEE) ISSN : 2278-3075, Volume -9 Issue -253,

3)Jingyue Zhang , North China Electric Power University , Boading 07100, China( ESAT 2018), $4^{\text {th }}$ International Conference on Energy Science and Applied Technology AIP Conf. Proc. 2066, 020022 -1$02002-5$

4) Math. H.J.Bollen " Understanding Power Qualkity Problem" 2019. A JOHNWILEY \& SONS, INC.,PUBLICATION.

5) Padmavathi and K R Sudha, (2019) Optimal sizing and placement of Dynamic Voltage Restorer in the Distribution System using Firefly Algorithm,
International Journal of Energy Technology and Policy, Vol. 15,No.2/3, pp.148-165,

6) Report on Power Quality of Electric Supply to the consumers, (2018)Report published by Forum of Regulators,.

7). A Report on "Swachh Power -A Glimpse on Power Quality in India,(2015) Published by Power Grid Coroporation in India

8) Akagi, "New trends in active filters for power conditioning"(1996),IEEE Transactions on Industry Application, vol .32, pp 1312- 1322, .

9) J.A. Demcko and S.Sullivan, Power quality problems and solutions(1996) at Arizona public service company, 7th IEEE Int. Coni on Harmonics and Quality ofPower (ICHPQ), Las Vegas,NV, ,pp.348-353,

10)E.W.Gunther and H.Mehta, A survey of distribution system power quality-Preliminary results, 1995 IEEE Transactions on Power Delivery, vol.10,no.1, pp.322329 ,

11) M.H.J.Bollen,T. Tayjasajant, and G.Yalcinkaya,Assessmentofthe number of voltage sags experienced by a large industrial customer, ,1997 IEEE Transactions on Industry Applications, vol..33,no.6, ,pp.1465-1471

12) C. Pumar, J. Amantegui, J. R.Torrealday, and C. Ugarte, (1997)A comparison between DC and AC drivesas regards their behaviour in the presence of voltage dips:New techniques for reducing the susceptibility of AC drives, Int. Con! on Electricity Distribution fCIRED), , Birmingham, U.K., pp. 5-11,

13) J. Lamoree, D.Mueller,P. Vinett, W. Jones, andM. Samotyj, (1994 ) Voltage sag analysis case studies, IEEE Transactions on Industry Applications, vol.30,no.4, ,pp. 1083- 1089,

14) H.G. Sarmiento andE. Estrada, (1996 ) A voltage sag study inan industry with adjustable... speed drives, IEEE Industry Applications Magazine, vol.2,no.1, ,pp.16-19,

15) J.e. Smith,J. Lamoree, P.Vinett,T. Duffy, and M.Klein, .(1995 )The impact of voltage sag son industrial plant loads, Int. Con! Power Quality: End-use applications and perspectives (PQA...91), pp.171-178

16). E.G. Strangas, V.E. Wagner, and T.D. Unruh, (1996) Variable speed drives evaluation test, IEEE Industry Applications Society Annual Meeting, October,SanDiego,CA,pp.2239-2243.Arevisedversion of this paper appeared in IEEE Industry Applications Magazine, vol.4,no.1, pp.53-57

17) A. David, J.Maire,andM. Dessoude,(1994)Influence of voltage dip sand sag characteristics on electrical machines and drives: evaluation and perspective, Ird Int. Con! On Power Quality: End-use applications and perspectives, , Amsterdam, The Netherlands, 
18) E.W. Gunther andH.Mehta, (1996)A survey of distribution system power quality-preliminary results,IEEE Transactionson Power Delivery, vol.10,no.1, ,pp.322-329

19) R.C.Dugan,M.F. McGranaghan, and H.W.Beaty, Electric Power Systems Quality, McGraw Hill,NewYork

17.W.E.Kazibweand M.H.Sendaula,Electric Power Quality Control Techniq ues, Van Nostrad Reinhold,NewYork. 